Article

\title{
An Application of Remote Sensing Imagery for Geological Lin- eaments Extraction over Kaybarkuh Region in East of Iran
}

\author{
V. Khademi ${ }^{1}$, M. R. Heyhat ${ }^{1}$, A. Forghani ${ }^{2,}{ }^{*}$, M. M. Khatib ${ }^{1}$, M. H. Zarrinkoub ${ }^{1}$, H. Hadizadeh Khader ${ }^{3}$ \\ ${ }^{1}$ Department of Geosciences, University of Birjand, Iran \\ 2 Science, Technology, Engineering and Mathematics (STEM), University of South Australia (UniSA), Ade- \\ laide, Australia; and Faculty of Science \& Technology, University of Canberra (UC), Canberra, Australia, \\ Australia \\ ${ }^{3}$ Geological Survey of Iran, Northeast Territory, Mashhad, Iran \\ *Correspondence: a.forghani@unisa.edu.au
}

How to cite this paper: Khademi, $\mathrm{V}$., Heyhat, M. R., Forghani, A., Khatib, M. M., Zarrinkoub, M. H., \& Khader, H. H. (2021). An Application of Remote Sensing Imagery for Geological Lineaments Extraction over Kaybarkuh Region in East of Iran. World Journal of Geomatics and Geosciences, 1(1), 50-59. Retrieved from https://www.scipublications.com/journal/index.php/wjgg/article/view/168

Received: October 29, 202 Accepted: December 17, 2021 Published: December 18, 2021

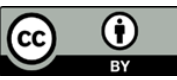

Copyright: (c) 2021 by the authors. Submitted for possible open access publication under the terms and conditions of the Creative Commons Attribution (CC BY) license (http://creativecommons.org/licenses /by/4.0/).

\begin{abstract}
Kaybarkuh (Mount Kaybar) consists of intrusive igneous bodies with two age periods, located in North of Dasht-e-Bayaz left-lateral fault terminal. The spatial and structural analysis of fractures and dike networks may allow for the accurate identification of mineralization zones in the area. This study aims to characterize lineament network in the study area by automatic method using multispectral satellite images from Landsat 8 Operational Land Imager (OLI), visual extraction of lineaments from Landsat- 8 and SENTINEL-2 images, and extraction of drainage network as lineament based on digital elevation models (DEMs) and their validation, compared with fault network of the area. The results showed that there is a significant relationship between the trend of studied lines in the region by the three methods mentioned and the overall trend is about N330. This can indicate a tensile regime with a trend perpendicular to the mentioned orientation, which results from the activity of the Dasht-e-Bayaz fault. Finding more evidences requires further studies.
\end{abstract}

Keywords: Kaybarkuh, Remote Sensing, Landsat 8, DEM, Lineaments

\section{Introduction}

In the past years, lineament analysis has become an important analytical technique for delineation of major structural units in mineral prospecting, hydrogeology, and tectonic studies [1]. In remote sensing images, geological lineaments show up as lines or linear structures that are significantly brighter or darker than the background pixels [2]. Genetically, three types of lineaments are separated; (i) geological lineaments, (ii) Geomorphological or topographic lineaments, and (iii) Pseudo, manmade, or non Geological lineaments [3]. Lineaments related to fractures may provide pathways for fluid flow and contribute to the formation of many economically significant oil, geothermal, and water supply reservoirs. Fracture systems control the dispersion of chemical contaminants into and through the subsurface [4]. The technology of geological lineaments extraction is of great significance for the analysis of regional plate movement and ore forming prognosis. However, the traditional methods are mainly based on the semi-automatic or manual visual interpretation, which consuming time and labor for the dependence on the rich professional experience and knowledge of the interpreter experts, and involving less in the special geomorphological regions [5].

The first Landsat satellite, launched in 1972 within the Landsat Data Continuity Mission, has a nearly 42-year global record. Two generations of Landsat satellites have now been launched by the National Aero-nautics and Space Administration and the United States Geological Survey. The first generation (Landsat-1, -2 and -3) operated from 1972 
to 1985 and has essentially been replaced by the second generation (Landsat- $4,-5$ and -7 ). Landsat-6, launched in 1993, failed to enter orbit [6].

Landsat-8 was launched on 4 February 2013 from Vandenberg Air Force Base in California. It is an American Earth observation satellite and joins Landsat-7 on-orbit, providing increased coverage of the Earth's surface. It is a free-flyer spacecraft carrying two sensors, the Operational Land Imager (OLI) and the Thermal Infrared Sensor (TIRS). These two instruments collect images for nine visible, near-infrared and shortwave infrared bands and two long-wave thermal bands. They have high signal-to-noise radiometer performance, allowing 12-bit quantification of data, thus providing more bits for better landcover characterization. Landsat- 8 pro- vides moderate-resolution imagery, from 15 to $100 \mathrm{~m}$ of the Earth's surface and polar regions [7-9].

Table 1. Performance characteristics of the Landsat-8 OLI/TIRS sensors

\begin{tabular}{cccccc}
\hline $\begin{array}{c}\text { Band } \\
\text { number }\end{array}$ & $\begin{array}{c}\text { Band } \\
\text { name }\end{array}$ & $\begin{array}{c}\text { Center } \\
\text { wavelength } \\
\text { (nanometers) }\end{array}$ & $\begin{array}{c}\text { Minimum lower } \\
\text { band edge } \\
\text { (nanometers) }\end{array}$ & $\begin{array}{c}\text { Maximum upper } \\
\text { band edge (nanometers) }\end{array}$ & $\begin{array}{c}\text { Ground } \\
\text { resolution (square meters) }\end{array}$ \\
\hline 1 & Coastal aerosol & 443 & 433 & 453 & 30 \\
2 & Blue & 482 & 450 & 515 & 30 \\
3 & Green & 562 & 525 & 600 & 30 \\
4 & Red & 655 & 630 & 680 & 30 \\
5 & NIR $^{1}$ & 865 & 845 & 885 & 30 \\
6 & SWIR $^{2}$ & 1,610 & 1,560 & 1,660 & 30 \\
7 & SWIR 2 & 2,200 & 2,100 & 2,300 & 30 \\
8 & Panchromatic & 590 & 500 & 680 & 15 \\
9 & Cirrus & 1,375 & 1,360 & 1,390 & 120 \\
10 & TIR 1 & 10,800 & 10,300 & 11,300 & 120 \\
11 & TIR 2 & 12,000 & 11,500 & 12,500 & \\
\hline
\end{tabular}

The Shuttle Radar Topography Mission (SRTM) datasets result from a collaborative effort by the National Aeronautics and Space Administration (NASA) and the National Geospatial-Intelligence Agency (NGA - previously known as the National Imagery and Mapping Agency, or NIMA), as well as the participation of the German and Italian space agencies. Together, this international space collaboration generates a near-global digital elevation model (DEM) of the Earth using radar interferometry.

SRTM was the primary, and virtually only, payload on the STS-99 mission of the Space Shuttle Endeavour, which launched February 11, 2000 and flew for 11 days. Following several hours for instrument deployment, activation, and checkout, systematic interferometric data were collected within a 222.4-hour period. The instrument operated almost flawlessly and imaged 99.96 percent (\%) of the targeted landmass at least one time, $94.59 \%$ at least twice, and about $50 \%$ at least three or more times. The goal was to image each terrain segment at least twice from different angles (on ascending, or north-going, and descending, or south-going, orbit passes) to fill areas shadowed from the radar signal by terrain [10].

\footnotetext{
1 Near infrared

2 Short wave infrared

3 Thermal infrared
} 
The full SENTINEL-2 mission comprises twin polar-orbiting satellites in the same orbit, phased at $180^{\circ}$ to each other. The mission will monitor variability in land surface conditions, and its wide swath width and high revisit time (10 days at the equator with one satellite, and 5 days with 2 satellites under cloud-free conditions which results in 2-3 days at mid-latitudes) will support monitoring of changes to vegetation within the growing season. The coverage limits are from between latitudes $56^{\circ}$ south and $84^{\circ}$ north. SENTINEL-2 will carry an optical instrument payload that will sample 13 spectral bands: four bands at $10 \mathrm{~m}$, six bands at $20 \mathrm{~m}$ and three bands at $60 \mathrm{~m}$ spatial resolution. The orbital swath width will be $290 \mathrm{~km}$. [11]

\section{Study area}

The study area is located in the Eastern terminal of sinistral Dasht-e-Bayaz fault with an approximate area of $570 \mathrm{~km}^{2}$ in East of Iran (Figure 1-a). Geographical range of the area is $34^{\circ} 0^{\prime} 0^{\prime \prime}-34^{\circ} 17^{\prime} 24^{\prime \prime} \mathrm{N}$ and $59^{\circ} 34^{\prime} 0^{\prime \prime}-59^{\circ} 54^{\prime} 32^{\prime \prime}$ E. Kaybarkuh consists of two intrusive igneous bodies including granite and granodioritic mass with age of Cretaceous in North, and a Paleocene basalt - andesitic body in South, that southern part is the goal of this study (Figure 1-b). There are plenty of sinistral strike-slip faults and North-South and West-East direction dykes in Southern part. In this part, vein mineralization is visible in boundary and fractures of masses that include two following types: 1 . Veins with galena, sphalerite, and barite as primary minerals depending to first generation of mineralization. 2. Veins with pyrite, chalcopyrite, and quartz as primary minerals, and covellite, bornite, chalcosite, malachite, azurite, and iron oxides as secondary minerals from second generation of mineralization. Trend of veins containing ore minerals such as copper is generally N-NW especially in southern part of Kaybarkuh.

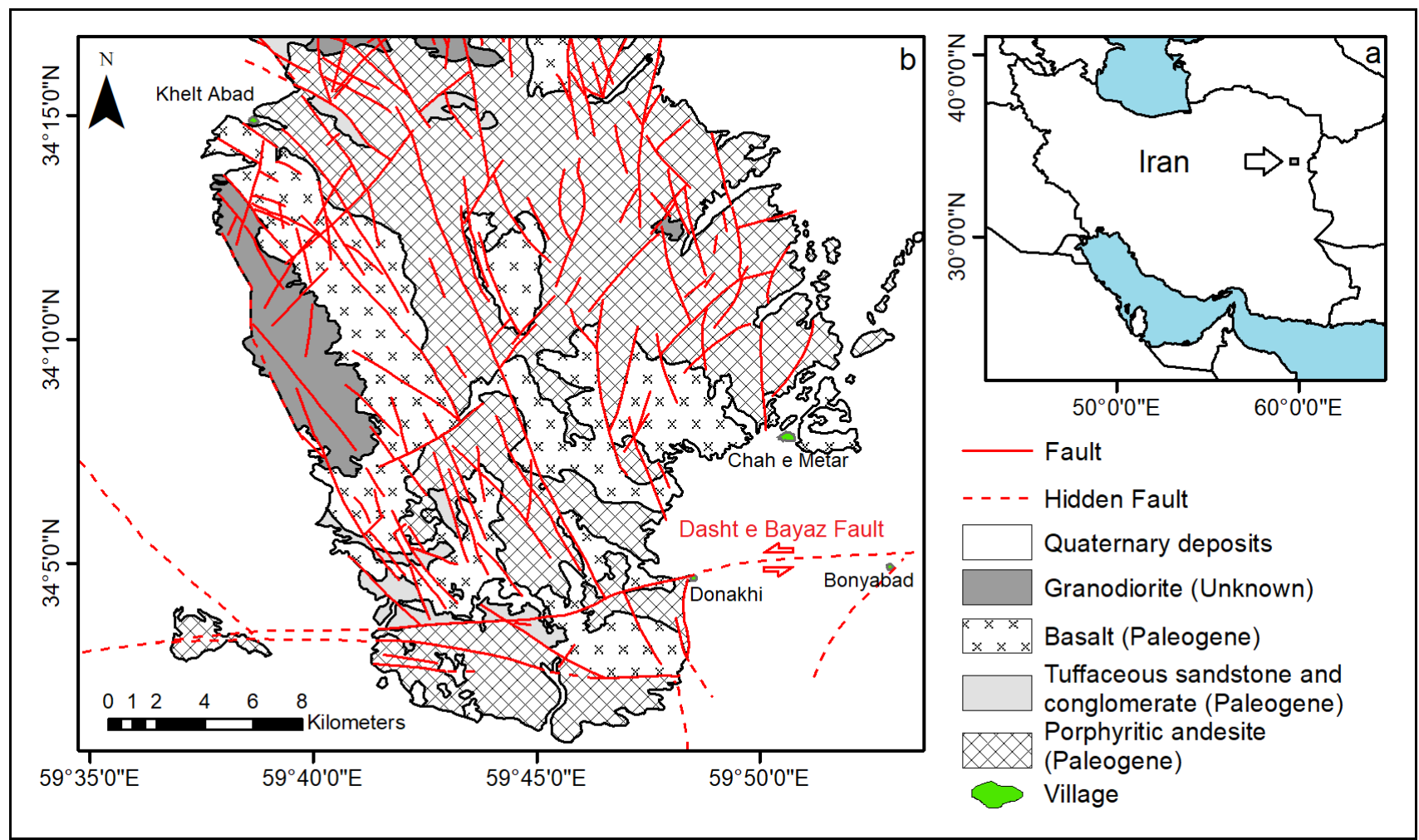

Figure 1. a. Location of study area on map of Iran. b. Geological setting of the study area (Modified from 1:100,000 Geological map of Zouzan, 2005). 


\section{Methodology}

Our methodology involves an analysis of geological lineaments of the study area that was performed by using below three methods:

\subsection{DEM Extraction}

Active deformation in tectonically active region has a significant influence on the drainage network behavior $[12,13]$. Drainage networks are key factors for investigating the regional tectonic activity, and deformational process of active faults $[14,15]$.

To extract drainage, we used DEM tiff image downloaded from SRTM digital elevation data at USGS website. The process of extraction performed in Arcmap environment as shown in (Figure 2). To reduce accidental occurrences and better tectonic-related valleys reveal, extracted lines were divided into separate sections based on the direction by the Polar Plot tool, then sections shorter than 200 meters were removed. The result polyline shapefile was clipped by rocky outcrop border to ignore the streams in the Quaternary units.
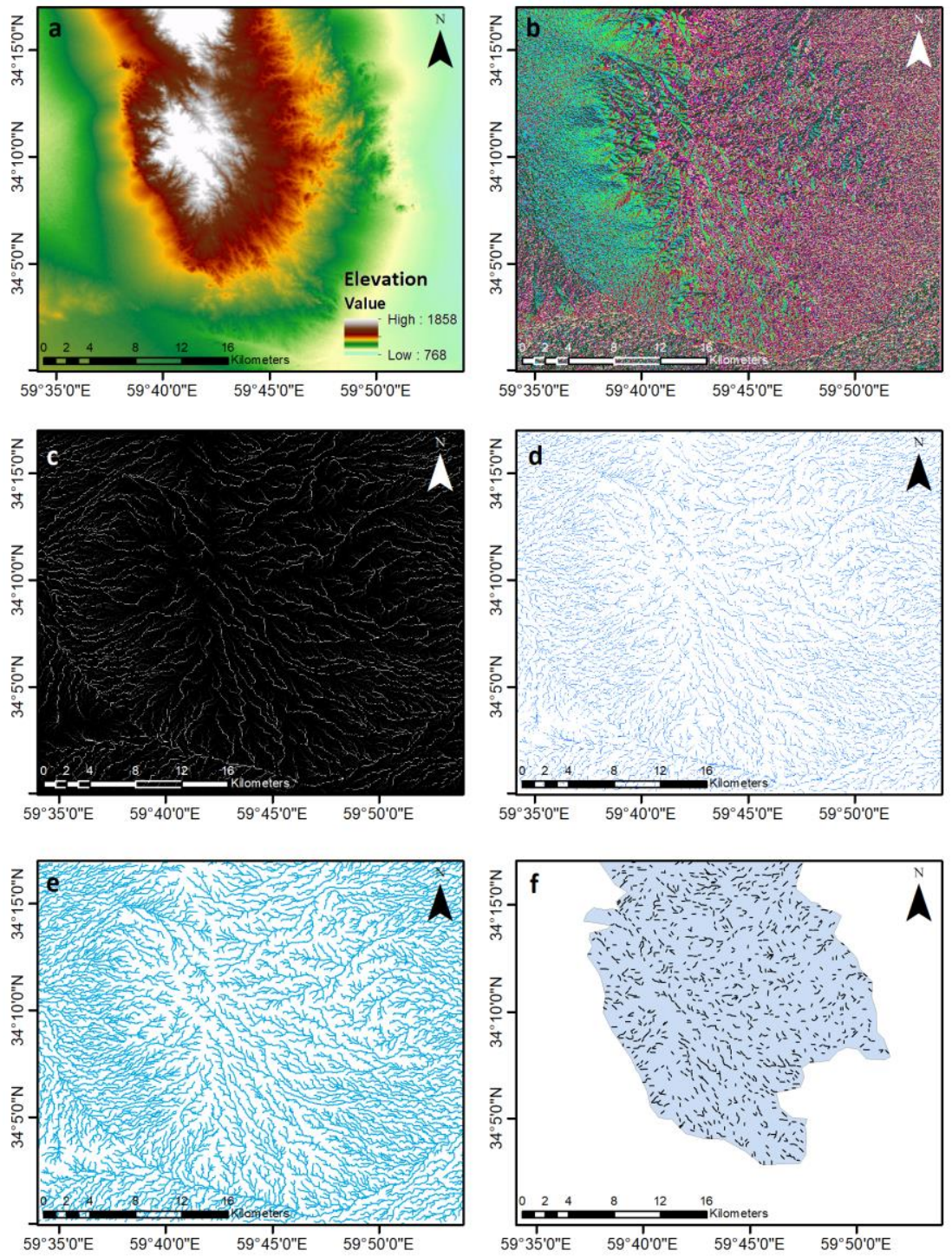

Figure 2. Extraction process of lineaments from drainage network using DEM image. a. Normal elevation map. b. Flow direction. c. Flow accumulation. d. Conditional raster. e. Drainage polylines resulted from raster. f. clipped and segmented polylines. 


\subsection{Automatic Lineament Extraction}

Although visual extraction of lines is the most common method, automatic line detection methods can greatly reduce user error and even identify lines that are not easily recognizable to the naked eye. To extract lineaments of the study area automatically, we used landsat- 8 image with applying some of image processing methods to enhance the edge and direction of lineaments.

One of the common problems in remote sensing and high resolution image processing is the need for somehow fusing lower resolution, multispectral (MS) bands such as Red, Green, Infrared, etc., with the single, higher resolution Pan band. Ideally, the MS bands can be up-sampled to the full Pan resolution without altering their spectral properties. Since its publication in 1998, the Gram-Schmidt pan-sharpen method has become one of the most popular algorithms to pan-sharpen multispectral (MS) imagery. It outperforms most other pan-sharpen methods in both maximizing image sharpness and minimizing color distortion [16].

Lineaments were extracted by using sufficient values of PCI Geomatica LINE module parameters software. PCI LINE (PCI Geomatics) offers an alternative, widely applied and robust method to automatically extract lineaments. The basic approach of PCI Line is similar to the object based approach. The only difference is the fact that the PCI line bases on the robust Canny edge detection algorithm. [17]. Classification accuracy evaluation demonstrated that the Canny edge filter gives best results among tested algorithms [18]. The properties of used image are [2021-08-19, 08:39:39, Geometric RMSE model $=3.437$ ] . Automatically extracted lineaments were shown on Gram-Schmidt sharpened true color image (Figure 3-a), and PCI Geomatics processed image (Figure 3-b).
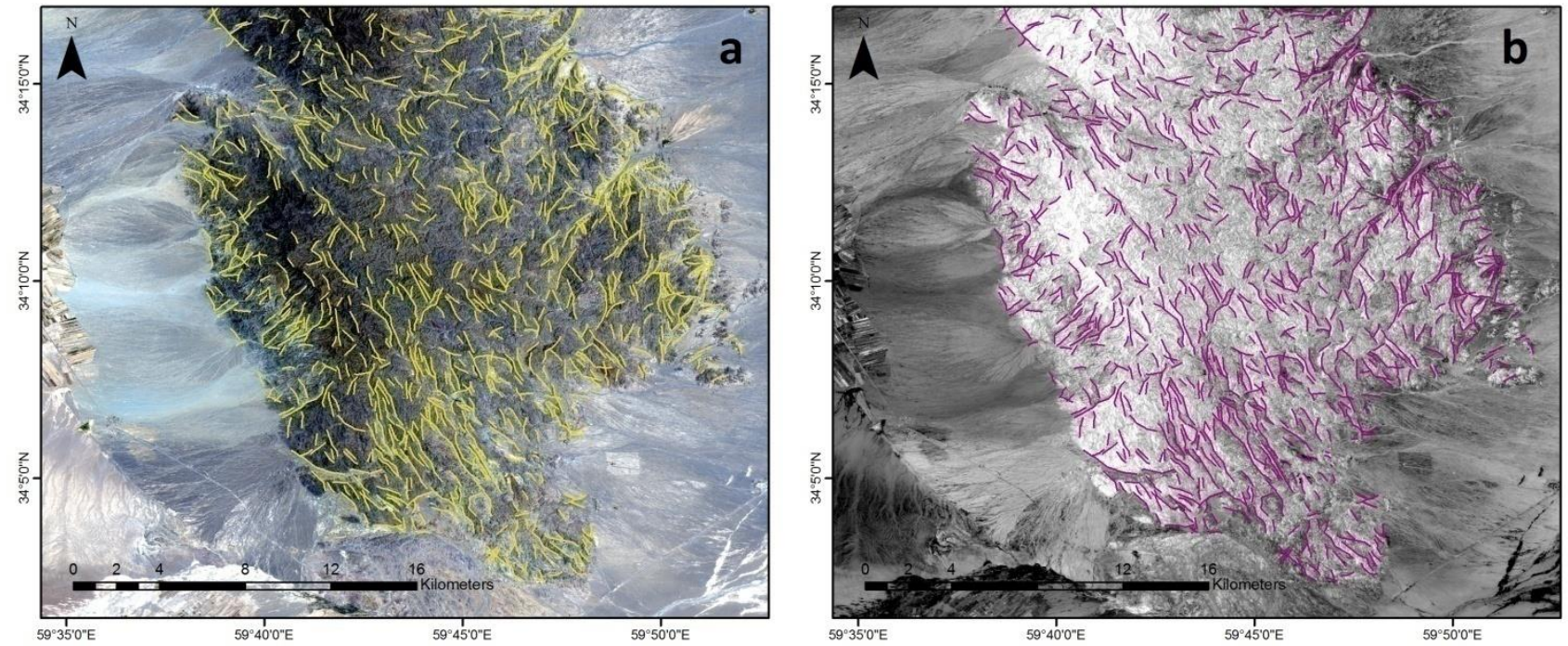

Figure 3. Automatically extracted lineaments on: a. Gram-Schmidt sharpened true color image, and b. PCI Geomatics processed image.

\subsection{Visual Lineament Extraction}

Visual identification of lineaments is mainly based on the experience of the operator [1]. By using visual interpretation in GIS software, all fault lines in the area were extracted on images obtained by applying directional filters, principal component analysis, band ratios, and color composition. In extracting lineaments, several markers were used including displacements of layers, rivers, and alluvial fans, linear vegetation, linear valleys, fault scarps, changes in the lithology, abrupt changes in slope and bed segments, fragmentation along outcrops, joints, and fractures. As shown in (Figure 4), the Sentinel-2 image with 
[12-4-2] band combination and Landsat-8 hill shaded images in GIS with [10, 100, and 230] azimuths were used for lineament detection.
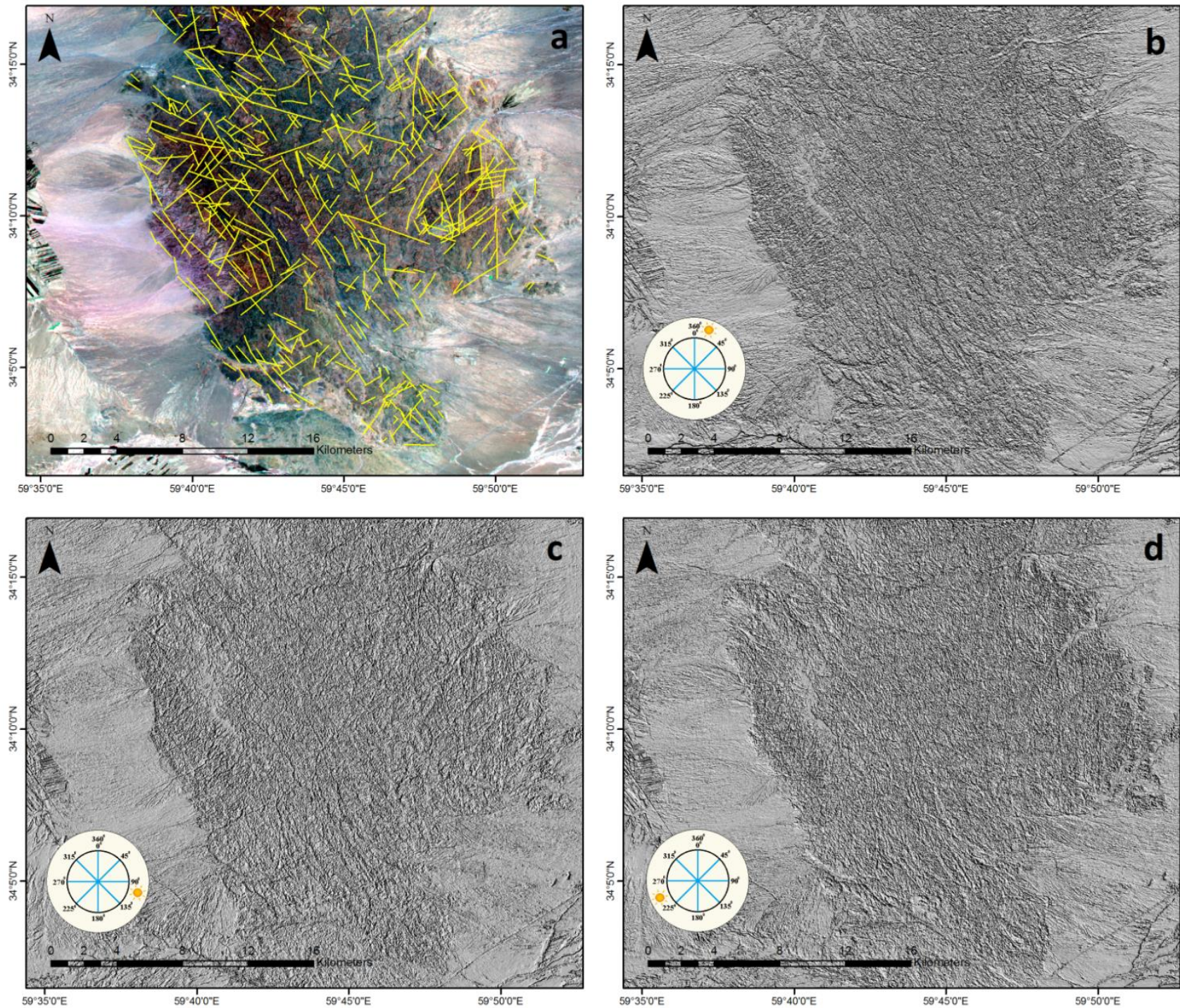

Figure 4. a. Visually extracted lineaments on Sentinel-2 (12-4-2) image, b. Hill shaded image with $10^{\circ}$ azimuth, c. Hill shaded image with $100^{\circ}$ azimuth, d. Hill shaded image with $230^{\circ}$ azimuth. 


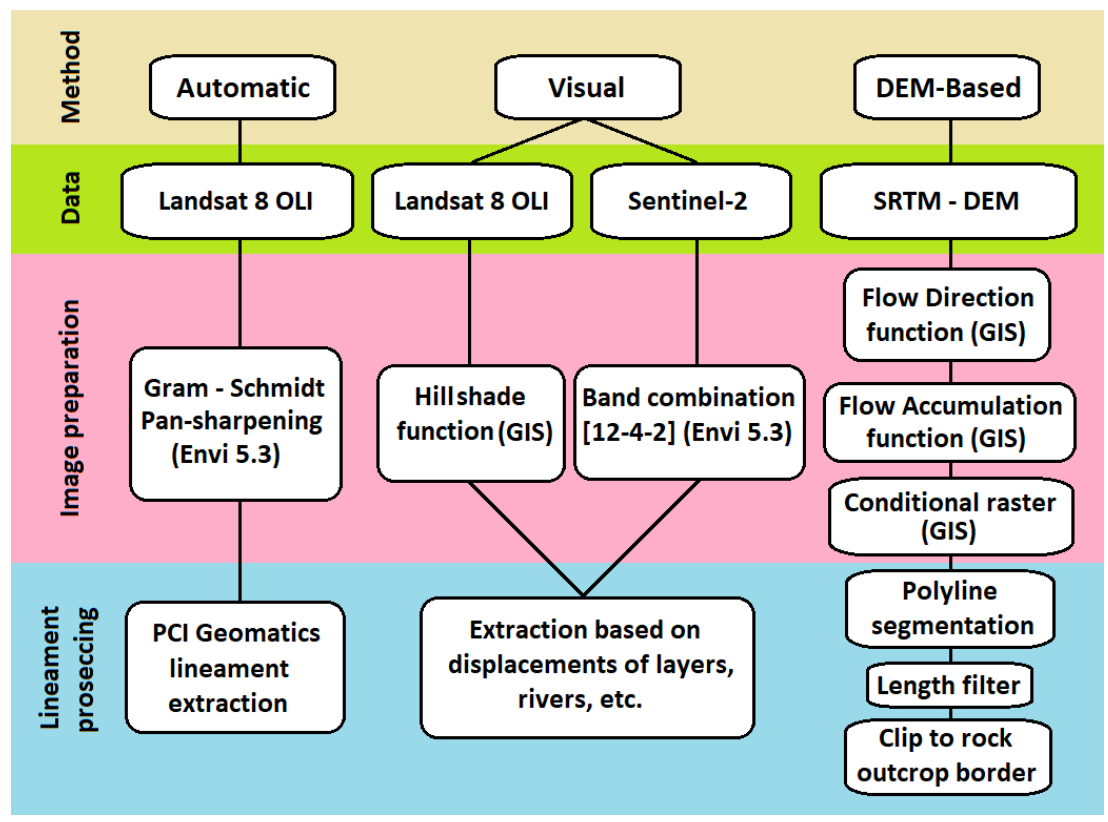

Figure 5. Flowchart of lineament extraction.

\section{Discussion}

After extracting, loading and comparing the lines in GIS software, we conclude that the obtained lines are in most cases compatible with each other (Figure 6). The statistical data of the extracted lineaments by three methods with the fault network of the region, taken from the 1:100,000 scale geological map, were shown in Figure 7. Excessive standard deviation of data in the fault network can be attributed to the small scale of the map used and the very long length of the fault lines. Figure 8 shows rose diagram of the resulting lineaments. Examination of the most numerous lines from DEM data shows that their main direction is East-West, which is probably due to the elongation of the outcrops in the North-South direction and the effect of topography. The second dominant direction in these lines is about $\mathrm{N} 330^{\circ}$ which is Aligned with the trend of lines in other methods.

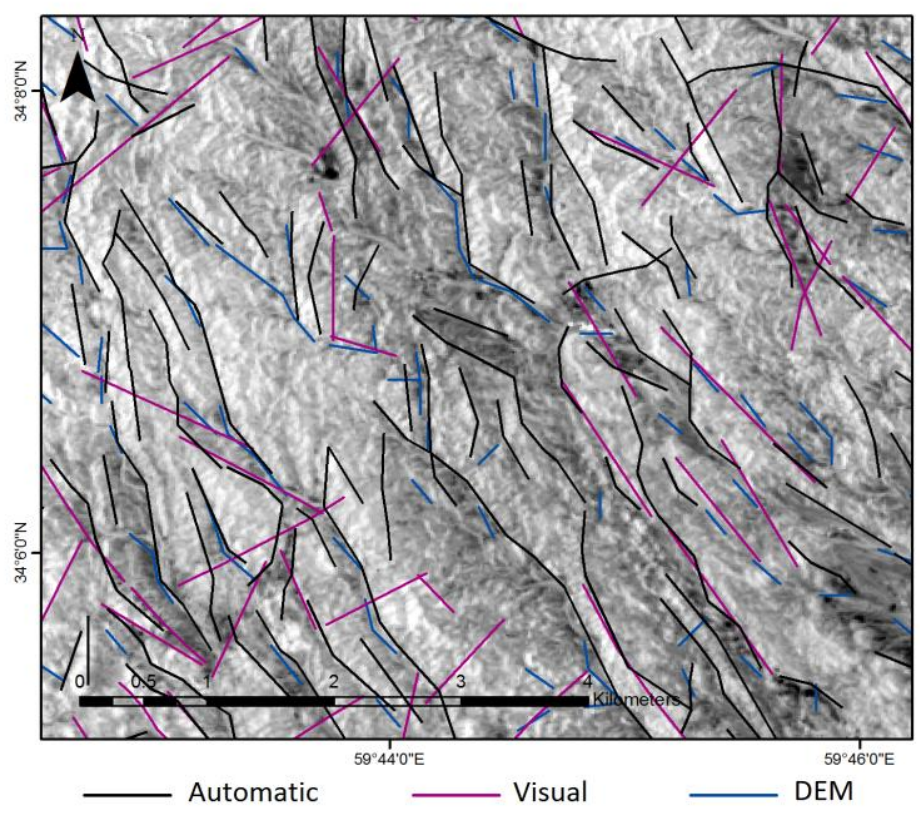

Figure 6. Plot of lineaments extracted by three methods on PCI Geomatics processed image. 

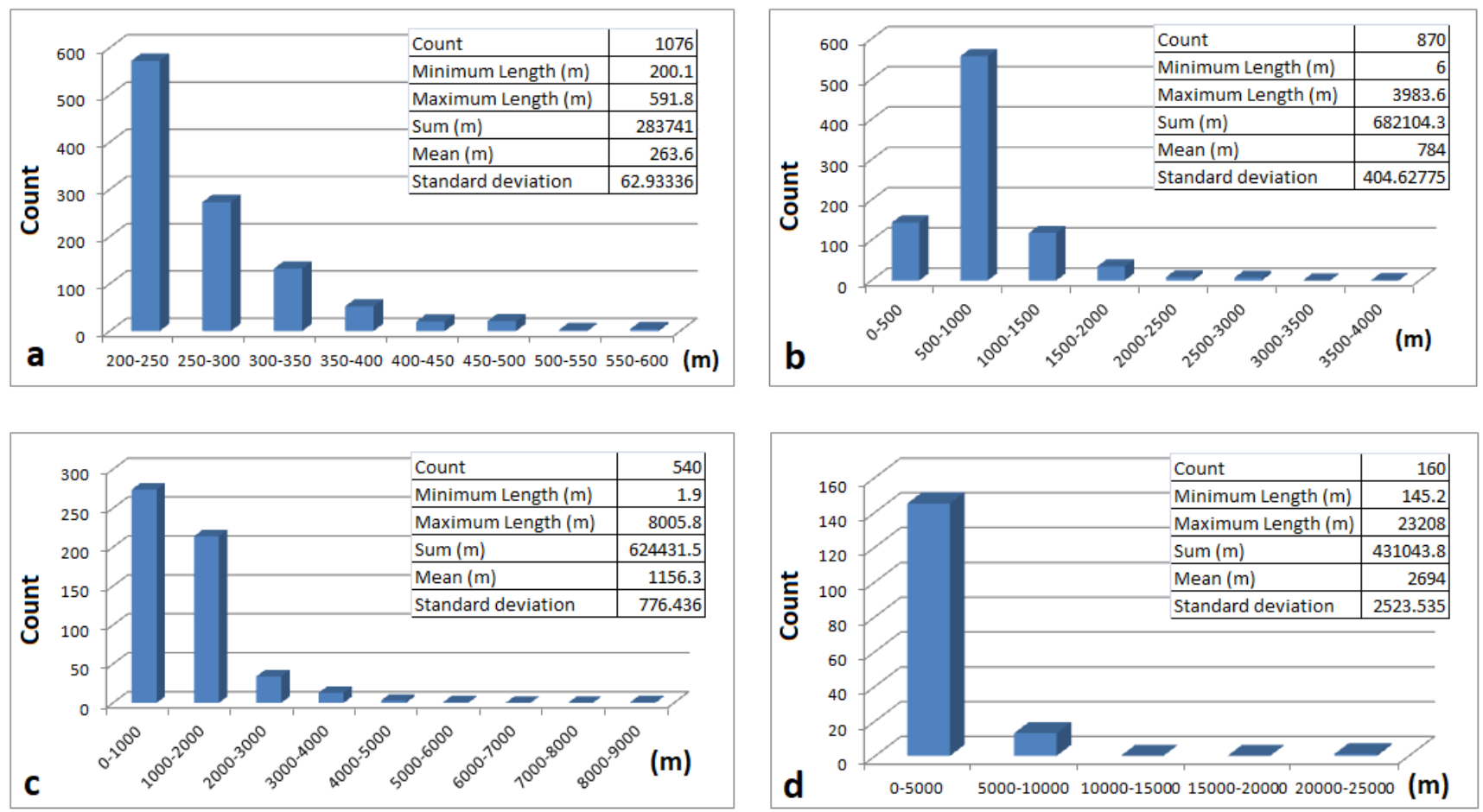

Figure 7. Statistical information of lineaments based on length and abundance for: $a$. DEM data, $b$. Automatic extraction, c. Visual extraction, and d. Fault network of the area. 

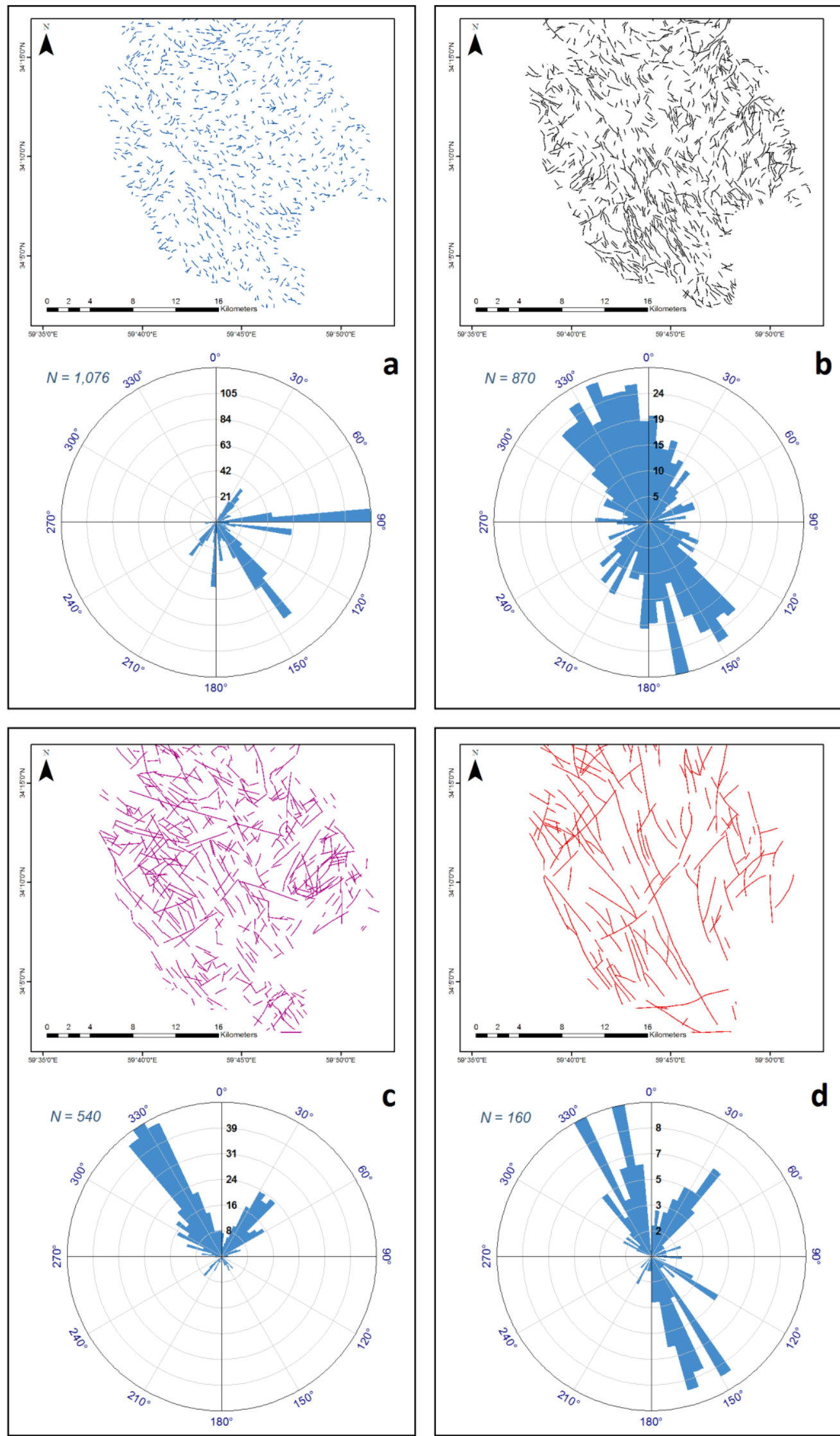

Figure 8. Comparison of lineaments resulted from: a. DEM data, b. Automatic extraction, c. Visual extraction, and $\mathrm{d}$. Fault network of the area, with related rose diagrams based on lineament trends. 


\section{Conclusion}

In this paper, we attempted for mapping lineaments and knowledgebase preparation using three methods for south of Kaybarkuh. Throughout this study, pan-sharpened Landsat-8 image was analyzed for automatic lineaments extraction under user suggested parameters values within LINE module of PCI Geomatica software. Also hill shaded images of mentioned satellite with three azimuths and Sentinel-2 image were used to extract lineaments visually. Finally, DEM data helped us to extract drainage network as structural lineaments. As it appears from the results, there is a significant relationship between the trends of structural lineaments resulted from the three methods. As shown in Figure 6, the general trend of lineaments is about $\mathrm{N} 330^{\circ}$. The study area is located in the northeastern part of the left-lateral Dasht-e-Bayaz fault terminal, so it can be concluded that the lines with mentioned trend were formed due to tension mechanism as normal faults, dikes or opened veins and the perpendicular lines, i.e. the trend of about $\mathrm{N} 60^{\circ}$ might be of the strike-slip type.

\section{References}

[1] Bonetto, S., Facello, A., Umili, G. (2017), A New Application of Curvatool Semi-automatic Approach To Qualitatively Detect Geological Lineaments. Environmental and Engineering Geoscience 23 (3): 179-190.

[2] Vassilas, N., Perantonis, S., Charou, E., Tsenoglou, T., Stefouli, M., Varoufakis, S., (2002), Delineation of lineaments from satellite data based on efficient neural network and pattern recognition techniques. 2nd Hellenic Conf. on AI, SETN-2002, 11-12 April 2002, Thessaloniki, Greece, Companion Volume, pp. 355-366. https://doi.org/10.1.1.75.6859.

[3] Soliman, A., Han, L. (2019), Effects of vertical accuracy of digital elevation model (DEM) data on automatic lineaments extraction from shaded DEM. Adv. Space Res, 64, 603-622.

[4] Masoud AA., Koike, K. (2006), Tectonic architecture through Landsat-7 ETM+/SRTM DEM-derived lineaments and relationship to the hydrogeologic setting in Siwa region, NW Egypt. J Afr Earth Sci 45(4-5): 467-477. https://doi.org/10.1016/j.jafrearsci.2006.04.005

[5] Han, L., Liu, Z., Ning, Y., Zhao, Z., (2018), Extraction and analysis of geological lineaments combining a DEM and remote sensing images from the northern Baoji loess area. Advances in Space Research 62 2480-2493.

[6] Sabins, F.F., (1999), Remote sensing for mineral exploration, Ore Geol. Rev. 14. 157-183.

[7] Beiranvand Pour, A., Hashim, M., (2015), Hydrothermal alteration mapping from Landsat-8 data, Sar Cheshmeh copper mining district, south-eastern Islamic Republic of Iran. Journal of Taibah University for Science 9, 155-166

[8] US Geological Survey., (2012), Landsat Data Continuity Mission. US Geological Survey, Washington, DC.

[9] Hearn, D.R., Digenis, C.J., Lencioni, D.E., Mendenhall, J.A., Evans, J.B., Walesh, R.D., (2001), EO-1 advanced land imager overview and spatial performance. IEEE Trans, Geosci, Remote Sens. 2, 897-899.

[10] US Geological Survey., (2015), The Shuttle Radar Topography Mission (SRTM) Collection User Guide, US Geological Survey, Washington, DC.

[11] European Space Agency, (2015), Sentinel-2 User Handbook. European Space Agency, Issue 1 Rev 2.

[12] Walker, F., Allen MB., (2012), Offset rivers, drainage spacing and the record of strike-slip faulting: The Kuh Banan Fault, Iran. Tectonophysics. 530-531:251-263.

[13] Sajadi, P., Singh, A., Mukherjee, S., Luo, P., Chapi, K., Salari, M., (2019), Multivariate statistical analysis of relationship between Tectonic Activity and Drainage Behavior in Qorveh-Dehgolan Basin Kurdistan, Iran. Geocarto International, DOI: https://doi.org/10.1080/10106049.2019.1611948

[14] Lin, A., Sun, Z., Yang, Z., (2008), Tectonic relationship between the course change of the Yangtze River and Indo-Asia collision. Structural Geology: New Research.49

[15] Yan, B., Lin, A., (2015), Systematic deflection and offset of the Yangtze River drainage system along the strike-slip Ganzi-YushuXianshuihe Fault Zone, Tibetan Plateau. JGeo. 87:13-25.

[16] Maurer, T., (2013), How to Pan-Sharpen images using the Gram-Schmidt Pan-Sharpen method - a recipe. International Archives of the Photogrammetry, Remote Sensing and Spatial Information Sciences, Volume XL-1/W1, ISPRS Hannover Workshop, 21 24 May 2013, Hannover, Germany

[17] Mallast, U., Gloaguen, R., Geyer, S., Rödiger, T., Siebert, C., (2011), Derivation of groundwater flow-paths based on semi-automatic extraction of lineaments from remote sensing data, Hydrol. Earth Syst. Sci., 15, 2665-2678, https://doi.org/10.5194/hess15-2665-2011.

[18] Forghani, A., (2000), Semi-automatic detection and enhancement of linear features to update GIS files. Proceedings of the XIXth ISPRS Congress, Amsterdam, Netherlands, CD-ROM procs, 8pp. 